\title{
Illustrations of Financing and Tax Transfers in Owner Financed Real Estate Sales
}

\author{
James Ang \\ Florida State University \\ Raymond Chiang \\ University of Miami \\ John B. Corgel \\ Georgia State University
}

The dramatic increase in seller or creative financing in the late 1970s and early 1980s has captured the attention of many academicians and practitioners. The primary focus in the existing literature is on explaining differences in loan terms between creative financing and conventional financing and on how these differences are capitalized into sale prices. This paper investigates the role of financing opportunity costs and federal income taxation and their consequences on real estate financing. Illustrations of the model show the feasibility of interpersonal financing transfers (between buyers and sellers) and intertemporal tax transfers (across time periods).

\section{Introduction}

Historically, the proportion of real estate sales in which some part of the contract price is financed by the owner has been quite small. At times during the past few years, however, presumably because of high interest rates and changes in tax laws governing installment sales, this proportion has become quite high.

Also in recent years the academic and professional literature on how buyers and sellers interrelate in financial contracts associated with real estate sales has grown dramatically. The major concerns in these studies have been with: 1) the allocation among buyers and sellers of selling price premiums or discounts resulting from nonconventional financing such as Federal Housing Administration/Veterans Administration mortgages, ${ }^{1}$ loan assumptions, ${ }^{2}$ and buy downs, ${ }^{3}$ and 2 ) the techniques used by real estate appraisers for estimating these price effects. ${ }^{4}$ With the exception of Hendershott (1982) who outlines some potential tax savings from owner financing contracts and Karlinsky and Kushel (1983) who compare cash flows from several creative financing arrangements, questions involving the tax implications of owner financing and the financing compatibility of buyers and sellers in such arrangements have not been examined, much less examined in any comprehensive fashion.

The nontax advantages to buyers and sellers of entering into owner financing agreements are well-known. Sellers agree to such arrangements to avoid costs associated with time-on- the-market. Buyers are motivated by opportunities to preserve below market rates on existing mortgages and seek to avoid high closing and financing costs incurred when taking out a new mortgage from an institution. Our paper focuses on the advantages to buyers and sellers with different opportunity costs of entering into owner financing agreements and on certain tax advantages of such agreements. Specifically, our

\footnotetext{
${ }^{1}$ See Zerbst and Brueggeman (1977) and Colwell, Gunterman, and Sirmans (1979). For a review see Gunterman (1982).

${ }^{2}$ See Sirmans, Smith, and Sirmans (1983) and Ferreira and Sirmans (1985).

${ }^{3}$ See Agarwal and Phillips (1983).

${ }^{4}$ See, for example, Findlay and Fischer (1983) and Corgel and Goebel (1983).
} 
purpose is to show how buyers and sellers can use alternative financing arrangements to facilitate transfer schemes between them. Such transfers permit two parties to improve their wealth positions simultaneously by an appropriate alignment of financing terms.

\section{General Model of Real Estate Transactions ${ }^{5}$}

A general real estate transactions model is used here to examine the structure of after-tax, incentive compatible transfers between buyers and sellers. To begin, we make some simplifying assumptions. First, transactions are assumed to involve only two parties - a representative buyer and a representative seller. Second, the mortgage is assumed to be riskless. Third, the imputed rental income exclusion is ignored since the model focuses on the actual cash flows of the buyer and seller. The mortgage loan is perpetual (i.e., nonamortizing, with periodic interest payment only). ${ }^{6}$ Finally, we assume that the capital gains tax is nonnegative, that is, the contract price is at least as great as the sum of the base price and the roll over allowance.

The payment and receipt schedules of the buyer and seller at contract price $P$, where $P$ is paid in cash (i.e., all equity financing), are shown in Table 1 . The symbols $C$ and $R$ represent the seller's cost basis in the property and roll over allowance (or exclusion) on the capital gain from the sale and ${ }^{\tau_{\mathrm{sg}}}$ is the seller's capital gain tax rate.

Table 2 provides the payment and receipt schedules of the buyer and seller from the same transaction, but now involving intermediary financing. In creating a mortgage contract, three essential contract provisions can be manipulated - the amount of the down payment, $D$, the size of the initial loan balance or remaining loan balance, $L$, and the loan rate or yield, Y. In

Table 1. Cash Flows from a Real Estate Transaction with All-Equity Financing

\begin{tabular}{|c|c|c|}
\hline & $t_{0}$ (Current Period) & $\begin{array}{c}\text { Subsequent Cash Flow } \\
\text { Per Period }\end{array}$ \\
\hline \multicolumn{3}{|c|}{ Buyer's Payment } \\
\hline Before Tax & $-P$ & 0 \\
\hline After Tax & $-P$ & 0 \\
\hline \multicolumn{3}{|l|}{ Seller's Receipt } \\
\hline Before Tax & $+P$ & 0 \\
\hline After Tax & $+P-(P-C-R) \tau_{\mathrm{sg}}$ & 0 \\
\hline
\end{tabular}

${ }^{5}$ This model is more fully developed in Ang, Chiang, and Corgel (1986).

${ }^{6}$ Technically, a perpetual mortgage is not really an installment sale. In an installment sale, a portion of the equity is repaid in every period. Thus, the capital gains savings from the tax rule would be less than the model implies. For example, at a $10 \%$ mortgage rate, the capital gains tax savings would be reduced, respectively, by $42 \%$ and $20 \%$ for a 15 -year and 30 -year mortgages. 
Table 2. Cash Flows from a Real Estate Transaction with Debt Financing (Intermediary)

Subsequent Cash Flow
Per Period

comparison to the cash flows resulting from all-equity financing (Table 1), conventional financing through an intermediary alters only the cash flows of the buyer. Consequently, the seller is indifferent between the all-equity deal and the intermediary financing arrangement since there is no change in his welfare. The buyer, however, will gain if the per dollar cost of financing is lower than the buyer's opportunity cost. ${ }^{7}$

In a perfect market with no transaction costs, the cost of financing and the opportunity costs of the buyer and seller are the same. However, that is atypical in real estate markets where information and transaction costs are high. In those markets, asymmetry in opportunity costs between the buyer and seller often exists. When the owner of the property provides financing for the buyer, the contract for sale includes the terms of the financing arrangement between the buyer and seller as well as the sale price they have negotiated. It is conceivable, therefore, that such an agreement can improve the wealth positions of both parties by spanning their investment opportunity set. Furthermore, aligning the contract terms in concert with internal revenue service (IRS) rules, the welfare of both parties can be enhanced.

For tax purposes, a transaction with owner financing would be considered an installment sale. ${ }^{8}$ Under current regulation for installment sale reporting, the seller reports the gross profit on the sale (defined as the contract price less the seller's adjusted basis) on a prorated schedule as payments are received in future tax years. ${ }^{9}$ The capital gains tax liability is based only on the profit percentage in each year. Thus, the present value of the tax payments is lowered, although total taxes paid by the seller during the life of the contract are the same as under the tax treatment for a normal sale (i.e., capital gain recognized totally in the year of sale) with either all equity or intermediary financing.

An owner financing arrangement is desirable, if and only if, it dominates the all-equity and intermediary-financing deals. Consider the possibility of an owner financing arrangement with the contract terms $(D+d),(L+I)$, and $(Y+y)$, where $d, I$, and y are changes in the down payment, mortgage loan size, and mortgage rate from those offered by the intermediary, respectively. Table 3 presents the

\footnotetext{
7Income tax has the same effect on the borrower's cost of financing and the buyer's opportunity cost.

${ }^{8}$ Discussions of the tax implications of installment sales are provided in Kau and Sirmans (1982), Jeddeloh and Perkins (1982), and Faggen et al. (1984) among other real estate income tax publications. Note that installment sale rules do not apply to losses.

${ }^{9}$ I.R.C. $§ 453$.
} 
cash flows resulting from an owner financing agreement, where ${ }^{\tau_{\mathbf{s}}}$ is the seller's tax rate in subsequent periods, $P^{\prime}$ is the new contract price with owner financing, and $a=(D+d) /(D+d+L+I)$, the percentage of the down payment (new) to contract price (new).

Table 3. Cash Flows from a Real Estate Transaction with Owner Financing

\begin{tabular}{|c|c|c|}
\hline & $t_{0}$ & $t_{i}(i=1, \cdots, n)$ \\
\hline \multicolumn{3}{|l|}{ Buyer } \\
\hline Before Tax & $-(D+d)$ & $-(L+l)(Y+y)$ \\
\hline After Tax & $-(D+d)$ & $-(L+l)(Y+y)\left(1-\tau_{b}\right)$ \\
\hline \multicolumn{3}{|l|}{ Seller } \\
\hline Before Tax & $+(D+d)$ & $(L+l)(Y+y)$ \\
\hline After Tax & $+(D+d)-a\left(P^{\prime}-C-R\right) r_{s g}$ & $(L+l)(Y+y)\left(1-\tau_{\mathrm{sg}}\right)$ \\
\hline
\end{tabular}

We are interested in the question of whether existing tax rules and opportunity cost asymmetry offer opportunities for welfare improving choices by the parties in owner financed sales. The answer lies in whether these asymmetries between the parties in such transactions can be converted into incentive compatible transfers.

Interpersonal opportunity cost asymmetry presents an opportunity for improving the wealth of the buyer and seller by reshuffling financing terms in the contract between the parties. Similarly, the difference between the seller's ordinary income tax rate, $\boldsymbol{\tau}_{\mathrm{S}}$, and capital gain tax rate, ${ }^{\boldsymbol{s}_{\mathrm{sg}}}$, combined with the tax savings from an installment sale, creates an opportunity for tax reduction via an intertemporal transfer. A general model is presented to facilitate the demonstration of how such tax transfers might operate in practice.

Let $B_{1}$ and $S_{1}$ be the discounted cash flows to the buyer and seller in an owner financed transaction, such that

$$
B_{1}=-(D+d)-\frac{(L+l)(Y=y)}{r_{b}},
$$

and

$$
S_{1}=(D+d)-\frac{d+D}{P^{\prime}}\left(P^{\prime}-C-R\right) \tau_{\mathrm{sg}}+\frac{(L+l)(Y+y)}{r_{\mathrm{s}}},
$$

where $r_{b}$ and $r_{s}$ are the before-tax opportunity costs of the buyer and seller, respectively. Tax rates have no effect on the present values of the interest expenses and incomes in Equations (1) and (2) since tax rates cancel in the numerators and denominators of the last term in both equations.

When $\mathrm{Y} / r_{b}$ is less than one (i.e., the buyer prefers financing), the incentive compatible condition for the owner financing is

$\Delta B, \Delta S \geq 0$, 
with strict inequality for at least one of the two conditions. Here $\Delta B$ and $\Delta S$, respectively, are differential savings to the buyer and seller from entering into an owner financing agreement versus the buyer obtaining financing through an intermediary. In a perfect market, $\mathrm{Y}, r_{b}$, and $r_{s}$ are equal and the capital gains tax is the only term that can result in a welfare improvement. However, in general

$\Delta B=-d-\frac{(L y+l Y+l y)}{r_{\mathrm{b}}}$,

and

$$
\Delta S=d+\left[\frac{L+l}{P^{\prime}}(P-C-R)-(d+l) \frac{D+d}{P^{\prime}}\right] \tau_{\mathrm{sg}}+\frac{(L y+l Y+l y)}{r_{\mathrm{s}}}+L\left(Y / r_{\mathrm{s}}-1\right) .
$$

The second term of Equation (5) is the seller's capital gains tax saving resulting from the installment sale and the change in contract price. The last term of the equation is the seller's gain (loss) from financing even if the contract terms are identical to those available from the intermediary. For example, if $\mathrm{Y} / r_{s}$ is greater than one, a gain is realized since the opportunity cost is low relative to $\mathrm{Y}$.

When $\mathrm{Y} / r_{s}$ is less than one, the buyer prefers the all-equity deal over financing through an intermediary. The resulting incentive compatible condition for owner financing is

$$
P-B_{1}, \quad \Delta S \geq 0 .
$$

Consequently, the buyer must realize savings from the owner financing arrangement vis-a-vis intermediary financing for an owner financing contract to be viable.

\section{Interpersonal Financing Transfer}

Since opportunities for interpersonal transfers emanate from a disparity between opportunity costs of buyers and sellers, interpersonal financing transfer schemes are facilitated by adjusting the interest payments (incomes) in the contract. The three forms of interpersonal transfers are as follows:

1. $Y / r_{\mathrm{b}}<1$ and $Y / r_{\mathrm{s}}>1$. It is in the interest of both parties to have owner financing.

2. $Y / r_{\mathrm{b}}<1$ and $Y / r_{\mathrm{s}}<1$. In this scenario, the buyer gains from owner financing while the seller loses. If the buyer can redistribute some of the gain back to the seller, a transaction could be completed with owner financing to the benefit of both parties.

3. $Y / r_{\mathrm{b}}>1$ and $Y / r_{\mathrm{s}}>1$. The results and their implications here are the mirror image of the second type of arrangement.

\section{Numerical Illustrations of Interpersonal Financing Transfer}

In a series of numerical examples, we demonstrate how interpersonal financing transfer schemes operate. Capital gains taxes are ignored in this part to isolate the effects of interpersonal opportunity cost asymmetry. The effects of capital gains taxes are examined later when considering intertemporal tax transfer. 
Any one-to-one tradeoff between the terms of an owner financing arrangement, the down payment (D), the mortgage loan amount $(\mathrm{L})$, and the mortgage yield or its equivalent $(\mathrm{Y})$, would be mutually beneficial in the first of the three cases cited above. Assume, for example, an owner financing transaction with the following set of terms and characteristics: $Y=12 \%, L=\$ 120,000, D=\$ 24,000$, $r_{b} 16^{2} \%$, and $r_{s}=10 \%$.

Therefore,

$$
\begin{aligned}
& Y / r_{\mathrm{b}}=\frac{0.12}{0.1666}=0.72<1, \\
& Y / r_{\mathrm{s}}=\frac{0.12}{0.10}=1.20>1 .
\end{aligned}
$$

Note that the buyer's per unit cost of financing is less than one, while the seller's per unit gain from financing is greater than one.

Now assume the same arrangement with the terms altered in the following way: $d=-\$ 10,000, I$ $=\$ 10,000$, and $y=0$ so that $D+d=\$ 14,000, L+I=\$ 130,000$, and $Y+y=12 \%$. The resulting gains to the buyer (i.e., cost savings) and seller are:

$$
\begin{aligned}
\Delta B & =\$ 10,000-\$ 10,000(0.72) \\
& =\$ 2,800, \\
\Delta S & =\$ 10,000+\$ 10,000(1.2)+\$ 120,000(1.2-1) \\
& =\$ 26,000 .
\end{aligned}
$$

These results occur even though the contract price remains unchanged. Furthermore, the welfare improvements are determined by the degree of asymmetry in opportunity cost between the buyer and seller.

In the second form of interpersonal transfer the condition that $r_{s}<r_{b}$ must also by met. Assume an arrangement with the following terms and characteristics: $Y=12 \%, L=\$ 120,000, D=\$ 24,000$, $r_{b}=16 \frac{2}{3} \%$, and $r_{s}=12.12 \%$ (note that $r_{s}<r_{b}$ ). Thus,

$$
Y / r_{\mathrm{b}}=\frac{0.12}{0.1666}=0.72<1 \text {, }
$$

and

$$
Y / r_{\mathrm{s}}=\frac{0.12}{0.1212}=0.99<1 \text {, }
$$

As in the previous example, we examine the changes in the buyer's and seller's wealth positions with a one-to-one tradeoff between the down payment and the mortgage loan amount. Let $d=-\$ 10,000, I=$ $\$ 10,000$, and $y=0$. Therefore, 
$\Delta B=\$ 2,800$,

$\Delta S=\$ 10,000+\$ 10,000(0.99)+\$ 120,000(0.99-1)$,

$=-\$ 1,300$.

Since the seller loses with this financing arrangement, the arrangement is not incentive compatible.

An incentive compatible contract can be created by having the trade-off between the down payment and mortgage loan amount different from one-to-one. Now let $d=-\$ 8,000, I=\$ 10,000$, and y $=0$. Recalculating the wealth positions of the buyer and seller yields

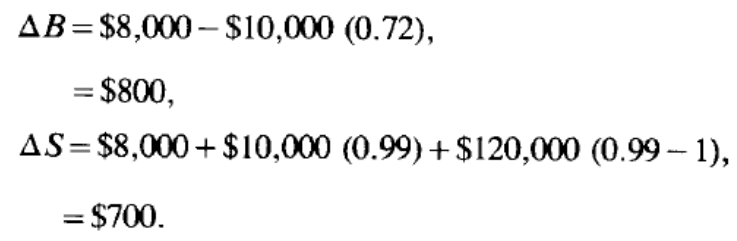

With this type of owner financing, the contract sales price is higher than in the case of conventional financing. To complete the transaction and the financing transfer, the decrease in the down payment must be smaller than the increase in the mortgage loan amount of yield equivalent, $-d / I<$ l. $^{10}$

For the third type of interpersonal transfer, the condition $r_{s}<r_{b}$ must be met in addition to those cited for the first type of arrangement. In this case, the seller's gain is more than the buyer's loss from the financing transfer. Thus, a side payment to the buyer in an amount that is, at least, equal to the buyer's loss will make the contract incentive compatible.

Assume a transaction with the following terms and characteristics: $Y=12 \%, L=\$ 120,000, D=$ $\$ 24,000, r_{b}=11.11 \%$, and $r_{s}=10 \%$. Note that

$Y / r_{\mathrm{b}}=\frac{0.12}{0.1111}=1.08>1$,

$Y / r_{\mathrm{s}}=\frac{0.12}{0.10}=1.20>1.08$.

By modifying the conventional financing contract terms asymmetrically for owner financing so that

\footnotetext{
${ }^{10}$ Note that the borrower is indifferent when $\Delta \mathrm{B}$ equals zero. Holding the mortgage yield constant, the indifference tradeoff between changes in mortgage size $\left(I^{*}\right)$ and down payment $d^{*}$ occurs at $d^{*}=-1 * Y / r_{b}$

Thus, the indifference points for the borrower in the second example are $(\$ 10,000,-\$ 7200)$ and $(\$ 11111,-\$ 8000)$. Similarly, the seller's indifference tradeoff occurs at

$d^{*}=-I^{*} Y / r_{s}+L\left(Y / r_{s}-1\right)$

The indifference points are therefore $(\$ 10000,-\$ 8700)$ and $(\$ 9293,-\$ 8000)$. Comparable analysis can also be performed for cases one and three.
} 
$\mathrm{d}=-\$ 11,000, I=\$ 10,000$, and $\mathrm{y}=0$, an incentive compatible contract is created. The changes in buyer and seller wealth are

$$
\begin{aligned}
\Delta B & =\$ 11,000-\$ 10,000(1.08), \\
& =\$ 200, \\
\Delta S & =-\$ 11,000+\$ 10,000(1.20)+\$ 120,000(1.20-1), \\
& =\$ 25,000 .
\end{aligned}
$$

The contract price in this owner financed transaction is lower than in the case of conventional financing because of a lower down payment or side payment to the buyer relative to the increase in the loan amount. As in the previous case, it can be shown that a symmetrical restructuring of terms is not incentive compatible.

\section{Intertemporal Tax Transfer}

Opportunities for intertemporal tax transfer result, in part, from seller tax rate asymmetry across time periods. Specifically, intertemporal tax transfer involves: 1 ) shifting of ordinary income to capital gains treatment and thus capitalizing on the rate differential between seller's ordinary income tax rate and capital gains tax rate, and 2) lowering the present value of capital gains tax liability through installment sale treatment. ${ }^{11}$

Three alternative strategies for an intertemporal tax transfer with owner financing are as follows:

1. The loan amount in the owner financing agreement is less than the loan amount with intermediary financing, but the rate is higher. The down payment is the same. In symbols, $I<0, \mathrm{y}>0$, and $\mathrm{d}=0$. This strategy requires that ${ }^{\tau_{\mathrm{sg}}}>0$.

2. The down payment in the owner financing agreement is less than the down payment with-intermediary financing, but the rate is higher. In symbols, $d<0, y>0$, and $I=0 .{ }^{12}$

3. The down payment in the owner financing agreement is larger than the down payment with intermediary financing, but the rate is lower. The loan amount is unchanged. In symbols, $\mathrm{d}>0, \mathrm{y}<0$, and $I=0 .{ }^{13}$

\section{Numerical Example of Intertemporal Tax Transfer}

As with the alternative interpersonal tax transfer arrangements, numerical examples are used to demonstrate how the three intertemporal tax transfer strategies work.

To examine the effects of a reduction in the loan amount $(I<0)$ and an increase in the rate $(y>$ 0 ) (i.e., strategy 1 ) relative to intermediary financing, the following terms and characteristics are assumed: $\mathrm{D}=\$ 24,000, \mathrm{~L}=\$ 120,000, \mathrm{Y}=12 \%{ }^{\tau_{\text {sg }}}=20 \%$, and $\mathrm{C}+\mathrm{R}=\$ 74,000$. Now let $\mathrm{I}=-\mathrm{Ly} /(\mathrm{Y}+\mathrm{y})$ (i.e., no change in the interest payment per period) and $d=0$, and $y=1 \%$. This implies that $I=-\$ 9,231$.

\footnotetext{
11 The tax transfer also depends on the seller's discount rate which can change over time.

12 the simplified form of the required condition for strategy 2 is $r_{b}>r_{s}$.

${ }^{13}$ The simplified form of the required condition for strategy 3 is $1-t_{s g}<r_{b} / r_{s}$
} 
In this case $\Delta \mathrm{B}$ and $\Delta \mathrm{S}$ are the buyer's and seller's gains from the tax transfer only. ${ }^{14}$ Therefore,

$$
\Delta B=0
$$

and

$$
\begin{aligned}
\Delta S & =\left[\frac{L+l}{P^{\prime}}(P-C-R)-l \frac{D}{P^{\prime}}\right] \tau_{\mathrm{sg}}, \\
& =\left[\frac{\$ 120,000-\$ 9,231}{\$ 144,000-\$ 9,231}(\$ 144,000-\$ 74,000)+\frac{(\$ 9,231) \$ 2,400}{\$ 144,000-\$ 9,231}\right] 0.20, \\
& =\$ 11,123 .
\end{aligned}
$$

As long as $\mathrm{Y} / \mathrm{rs}$ is greater than one, any loss from owner financing would not offset the gain from the tax transfer shown above as AS. The advantage of this strategy, which provides for an increase in $Y$ and reduction in $L$, is that $L$ is taxed twice while the income from $Y$ is taxed only once.

To examine the effects of a reduction in the down payment $(d<0)$ and an increase in the rate (y $>0$ ) as in strategy 2 , the following terms and characteristics are assumed: $D=\$ 24,000, L=\$ 120,000, C+$ $\mathrm{R}=\$ 74,000, \mathrm{Y}=12 \%, r_{S}=11.11 \%$, and $r_{b}=13.33 \% .{ }^{15}$

Now assume an owner financing contract with $y=1 \%, d=-\$ 9,100$, and $I=0$. The resulting changes in the buyer's (saving) and seller's (gain) wealth positions are

$$
\begin{aligned}
\Delta B & =\$ 9,100-\frac{0.01(\$ 120,000)}{0.1333}, \\
& =\$ 100, \\
\Delta S & =-\$ 9,100+\left[\frac{\$ 120,000}{\$ 134,900}(\$ 70,000)+\$ 9,100 \frac{\$ 14,900}{\$ 134,900}\right] 0.20+\frac{\$ 1,200}{0.1111}, \\
& =\$ 14,355 .
\end{aligned}
$$

In this case, $\Delta S$ includes the gains from financing (the last term of the above equation). The sum of the first four terms of $\Delta S$, which represents the benefit from tax transfer, is positive.

Finally, to examine the effects of an increase in the down payment $(d>0)$ together with a reduction in the rate $(+<0)$ relative to intermediary financing, the following terms and characteristics are assumed: $\mathrm{D}=\$ 24,000, \mathrm{~L}=\$ 120,000, \mathrm{C}+\mathrm{R}=\$ 74,000, \mathrm{Y}=12 \%,{ }_{\mathrm{Sg}}=1 \%, r_{s}=11.11 \%$, and $r_{b}=$ $10.91 \%$. Note that

$$
Y / r_{\mathrm{b}}=1.1, \quad Y / r_{\mathrm{s}}=1.08, \quad \text { and } \quad 1-\tau_{\mathrm{sg}}=0.99 \text {. }
$$

Now assume an owner financing contract with $d=\$ 10,900, y=-1 \%$, and $1=0$. The resulting change in the buyer's (savings) and seller's (gain) wealth positions are

\footnotetext{
${ }^{14}$ The term $L\left(Y / r_{s}-1\right)$ of Equation (5), the seller's gain, is ignored in every numerical example of intertemporal tax transfer to highlight the gain from the tax transfer.

${ }^{15}$ Note that $Y / r_{b}=0.90$ and $Y / r_{s}=1.08$ so the required condition is satisfied.
} 


$$
\begin{aligned}
\Delta B & =\$ 10,900-\frac{\$ 120,000(-0.01)}{0.1091}, \\
& =\$ 100, \\
\Delta S & =\$ 10,900+\left[\frac{\$ 120,000}{\$ 154,900}(\$ 70,000)-\$ 10,900 \frac{\$ 34,900}{\$ 154,900}\right] 0.01+\frac{\$ 1,200}{0.1111}, \\
& =\$ 618 .
\end{aligned}
$$

\section{Conclusions}

Owner financing of real estate is an interesting topic of study because it involves a merger of the contract for sale (i.e., investment decision) and the mortgage contract (i.e., financing decision). As evidenced by the empirical results of studies examining the effects of such mergers, the prices established in owner financed transactions often diverge from competitive market prices adjusted for below market financing. In addition, there is the related issue of consumer choice in the selection of owner financing over intermediary financing.

The examples presented in this paper have implications for both issues. By establishing the conditions for incentive compatible contracting between buyers and sellers (in which the contract includes both the terms of sale and the terms of financing), we demonstrate how interpersonal financing and intertemporal tax asymmetries can be converted into mutual welfare improvements. The choice between owner financing and intermediary financing depends on the relative magnitudes of $r_{b}$ and $r_{s} .{ }^{16}$ Under conditions which $r_{b}$ and $r_{s}$ are not simultaneously favorable to owner financing, the parties can still consummate an owner financed transaction by negotiating terms other than those involving one-to-one tradeoffs between $L$ and $D$. Side payments facilitate incentive compatible contracting but may result in prices that are higher than with conventional financing.

Intertemporal tax asymmetries can also lead to tax transfers in owner financial sales. These result from the ability to save tax payments through an intertemporal alignment of terms. Since the intermediary usually cannot participate in such tax transfer schemes, consumers have an additional incentive to choose owner financing.

\section{References}

Agarwal, V. B., and Phillips, R. A. Winter 1983. The effects of mortgage rate buy downs on housing prices: Evidence from FHA-VA transactions. AREUEA Journal 11:491-503.

Ang, J., Chiang, R., and Corgel, J. B. 1986. Taxes and real estate: The case of sell financing. Working Paper.

Brueckner, J. K. Winter 1984. Creative financing and house prices: A theoretical inquiry into the capitalization issue. AREUEA Journal 12:417-426.

\footnotetext{
${ }^{16}$ Brueckner (1984) has argued that consumer choice between intermediary and owner financing "will depend on the nature of his utility function and perhaps on the size of the home he wishes to buy."
} 
Colwell, P. F., Gunterman, K. L., and Sirmans, C. F. Sept. 1979. Discount of points and housing prices: Comment. Journal of Finance 34:1049-1054.

Corgel, J. B., and Goebel, P. R. Spring 1983. Financing adjustments via cash equivalency: Evidence on accuracy. Real Estate Appraiser and Analyst 49:55-61.

Faggen, I. et al. 1984. Federal Taxes Affecting Real Estate. Arthur Anderson Co. Albany, New York: Matthew Bender and Co., Inc.

Ferreira, E. J., and Sirmans, G. S. 1985. Assumable loans in creative financing. Housing Finance Review, forthcoming.

Findlay, M. C., and Fischer, F. E. Jan. 1983. On adjusting the price of 'Creatively Financed' residential sales: Cash equivalence vs. FFA. Housing Finance Review 2:63-80.

Gunterman, K. L. 1982. Financing and selling prices of single family homes. In C. F. Sirmans (ed.)

Research in Real Estate, Vol. 1:255-273, Greenwich, CT, JAI Press, Inc.

Hendershott, P. H. 1982. The development and future of owner financing. Quarterly Review, Federal Home Loan Bank of Cincinnati 12:14-17.

Jeddeloh, J. B., and Perkins, C. G. 1982. Real Estate Taxation, Reston Publishing Company, Inc.

Karlinsky, S., and Kushel, P. 1983. Everyone wants a home: An after-tax analysis of creative financing. New York University Working Paper.

Kau, J. B., and Sirmans, C. F. 1982. Tax Planning for Real Estate Investors. Englewood Cliffs, NJ, Prentice Hall, Inc.

Sirmans, F. S., Smith, S. D., and Sirmans, C. F. Sept. 1983. Determining the market value of assumable home loans. Journal of Financial and Quantitative Analysis 18:307-317.

Zerbst, R. H., and Brueggeman, W. B. Dec. 1977. FHA and VA mortgage discount points and housing prices. Journal of Finance 32:1766-1773. 